\title{
Sulfuritalea hydrogenivorans gen. nov., sp. nov., a facultative autotroph isolated from a freshwater lake
}

Correspondence

Hisaya Kojima

kojimah@pop.lowtem.hokudai.ac.jp

\author{
Hisaya Kojima and Manabu Fukui
}

Institute of Low Temperature Science, Hokkaido University, Kita-19, Nishi-8, Kita-ku, Sapporo 0600819, Japan

\begin{abstract}
A novel facultatively autotrophic bacterium, designated strain $\mathrm{sk} 43 \mathrm{H}^{\top}$, was isolated from water of a freshwater lake in Japan. Cells of the isolate were curved rods, motile and Gram-reactionnegative. Strain $\mathrm{sk} 43 \mathrm{H}^{\top}$ was facultatively anaerobic and autotrophic growth was observed only under anaerobic conditions. The isolate oxidized thiosulfate, elemental sulfur and hydrogen as sole energy sources for autotrophic growth and could utilize nitrate as an electron acceptor. Growth was observed at 8-32 ${ }^{\circ} \mathrm{C}$ (optimum $25^{\circ} \mathrm{C}$ ) and 6.4-7.6 (optimum pH 6.7-6.9). Optimum growth of the isolate occurred at $\mathrm{NaCl}$ concentrations of less than $50 \mathrm{mM}$. The $\mathrm{G}+\mathrm{C}$ content of genomic DNA was around $67 \mathrm{~mol} \%$. The fatty acid profile of strain $\mathrm{sk} 43 \mathrm{H}^{\top}$ when grown on acetate under aerobic conditions was characterized by the presence of $\mathrm{C}_{16: 0}$ and summed feature $3\left(\mathrm{C}_{16: 1} \omega 7 \mathrm{c}\right.$ and/or iso- $\left.\mathrm{C}_{15: 0} 2-\mathrm{OH}\right)$ as the major components. Phylogenetic analysis based on 16S rRNA gene sequences indicated that the strain was a member of the class Betaproteobacteria showing highest sequence similarity with Georgfuchsia toluolica $\mathrm{G} 5 \mathrm{G} 6^{\top}$ (94.7\%) and Denitratisoma oestradiolicum AcBE2-1 ${ }^{\top}$ (94.3\%). Phylogenetic analyses were also performed using genes involved in sulfur oxidation. On the basis of its phylogenetic and phenotypic properties, strain sk43H ${ }^{\top}\left(=\mathrm{DSM} 22779^{\top}=\mathrm{NBRC} 105852^{\top}\right)$ represents a novel species of a new genus, for which the name Sulfuritalea hydrogenivorans gen. nov., sp. nov. is proposed.
\end{abstract}

Members of the class Betaproteobacteria have highly diverse physiological properties and there are numerous combinations of electron donors and acceptors that can support their growth. Recently, it was demonstrated that toluene can serve as electron donor for $\mathrm{Fe}$ (III) reduction by a novel betaproteobacterial isolate, strain $\mathrm{G} \mathrm{G6}^{\mathrm{T}}$ (Weelink et al., 2009). This strain is closely related to the dominant phylotype in denitrifying enrichment cultures growing on p-xylene (Rotaru et al., 2010). In the present study, a novel bacterium closely related to these organisms was isolated and characterized. The novel isolate, designated strain sk $43 \mathrm{H}^{\mathrm{T}}$, was facultatively chemolithotrophic and was capable of growing on sulfur compounds and hydrogen under denitrifying conditions.

Strain sk $43 \mathrm{H}^{\mathrm{T}}$ was obtained from a water sample taken from Lake Mizugaki, a stratified artificial freshwater lake located in central Japan (Kojima et al., 2009). The sample was obtained at a depth of $30 \mathrm{~m}$, corresponding to the upper boundary of the hypolimnion. The basal medium

The GenBank/EMBL/DDBJ accession numbers for the 16S rRNA, aprA and soxB gene sequences of strain sk $43 \mathrm{H}^{\top}$ are AB552842, AB552843 and AB552844, respectively.

A supplementary table is available with the online version of this paper. used for enrichment and isolation was bicarbonate-buffered low-salt defined medium (Kojima \& Fukui, 2010), which comprised $\left(1^{-1}\right): 0.25 \mathrm{~g} \mathrm{NaCl}, 0.2 \mathrm{~g} \mathrm{MgCl}_{2} \cdot 6 \mathrm{H}_{2} \mathrm{O}, 0.1 \mathrm{~g}$ $\mathrm{CaCl}_{2} \cdot 2 \mathrm{H}_{2} \mathrm{O}, 0.1 \mathrm{~g} \mathrm{NH} 4 \mathrm{Cl}, 0.1 \mathrm{~g} \mathrm{KH}_{2} \mathrm{PO}_{4}, 0.1 \mathrm{~g} \mathrm{KCl}, 1 \mathrm{ml}$ trace element solution, $1 \mathrm{ml}$ selenite-tungstate solution, $1 \mathrm{ml}$ vitamin mixture solution, $1 \mathrm{ml}$ vitamin $\mathrm{B}_{12}$ solution, $1 \mathrm{ml}$ thiamine solution, $30 \mathrm{ml} \mathrm{NaHCO}$ solution and $1.5 \mathrm{ml}$ $\mathrm{Na}_{2} \mathrm{~S}_{2} \mathrm{O}_{3}$ solution. All stock solutions were prepared as described previously (Widdel \& Bak, 1992). To establish the first enrichment, $0.2 \mathrm{ml}$ lake water was inoculated into a bottle containing $20 \mathrm{ml}$ medium. Just before inoculation, anaerobic stock solution of $\mathrm{NaNO}_{3}$ was added to the bottle to obtain a final concentration of $25 \mathrm{mM}$. The headspace of the bottle was filled with $\mathrm{N}_{2} / \mathrm{CO}_{2}(80: 20, \mathrm{v} / \mathrm{v})$ and incubation was performed at room temperature in the dark for 6 months. After this time, a sample of the culture was diluted 100-200-fold by transferring into medium of the same composition to obtain subsequent enrichment cultures. The isolate was obtained from the third enrichment by using the agar shake dilution method (Widdel \& Bak, 1992). For the isolation procedure, thiosulfate concentration in the medium was raised to $20 \mathrm{mM}$. A well-separated colony was transferred to a slightly modified medium that contained $10 \mathrm{mM}$ thiosulfate, $20 \mathrm{mM}$ nitrate and no $\mathrm{NaCl}$. Purity of 
the isolate was tested by phase-contrast light microscopy and sequencing of $16 \mathrm{~S}$ rRNA gene fragments amplified with several universal PCR primer pairs.

Cell morphology was observed using phase-contrast microscopy. Gram-staining was tested with a commercially available kit (Fluka). Catalase activity was assessed by pouring a $3 \% \mathrm{H}_{2} \mathrm{O}_{2}$ solution onto a pellet of cells obtained by centrifugation. Oxidase activity was also tested with a pellet of cells by using a differentiation disk (Fluka).

For characterization of the strain, an $\mathrm{NaCl}$-free version of the basal medium containing $20 \mathrm{mM} \mathrm{NaNO}_{3}$ was used, unless otherwise specified, and cultures were incubated at $25{ }^{\circ} \mathrm{C}$ without shaking. Each experiment was performed in duplicate. Sensitivity to antibiotics was tested with kanamycin and ampicillin at $100 \mu \mathrm{g} \mathrm{ml}^{-1}$.

Utilization of electron acceptors was tested in medium without nitrate. Electron donor utilization was first tested under anoxic conditions by using basal medium with lowered thiosulfate concentration $(0.4 \mathrm{mM})$. Utilization of electron donors was also tested under aerobic conditions using a medium containing no $\mathrm{NaNO}_{3}$ or $\mathrm{NaHCO}_{3}$, which was buffered with $20 \mathrm{mM}$ MOPS/KOH. The effects of salt concentration $(0,20,50,100,150,180,200,220,240,260$, $280 \mathrm{mM} \mathrm{NaCl})$ and temperature $(2,5,8,13,20,22,25,28$, $30,32,34,37,42{ }^{\circ} \mathrm{C}$ ) on growth of the strain were tested under aerobic conditions by using MOPS-buffered medium supplemented with $16 \mathrm{mM}$ sodium acetate. Growth was tested at $\mathrm{pH}$ 6.0, 6.4, 6.5, 6.7, 6.8, 6.9, 7.1, 7.3, 7.6, 7.9, 8.2 and 9.0 in media that contained CAPSO $\left(11 \mathrm{~g} \mathrm{l}^{-1}\right)$, MOPS $\left(10 \mathrm{~g} \mathrm{l}^{-1}\right)$ and the required amount of $\mathrm{KOH}$ to adjust the $\mathrm{pH}$ level.

Changes in concentrations of nitrite, nitrate, sulfate and thiosulfate were monitored with an ion chromatograph (DX-120; Dionex) equipped with a column for anion analyses (IonPac AS4ASC; Dionex).

The genomic $\mathrm{G}+\mathrm{C}$ content of the DNA was determined by the fluorescence monitoring method (Gonzalez \& SaizJimenez, 2002). The fatty acid profile of the strain was analysed from biomass obtained after aerobic growth on MOPS-buffered medium with sodium acetate. Fatty acid analysis was performed at Techno Suruga (Shizuoka, Japan) by using the Sherlock Microbial Identification System (MIDI) according to the manufacturer's instructions.

A fragment of nearly full-length 16S rRNA gene was amplified with the primer pair 27F and 1492R (Lane, 1991) and then sequenced directly. Based on the obtained sequence, phylogenetic affiliation of the novel strain was deduced by using RDP Classifier (Wang et al., 2007) with a confidence threshold of $95 \%$. The 16S rRNA gene sequence of $s k 43 \mathrm{H}^{\mathrm{T}}$ was aligned with related sequences retrieved from DDBJ/EMBL/GenBank using the program CLUSTAL_X (Thompson et al., 1997). Genetic distances were calculated using the program MEGA3 (Kumar et al., 2004). Partial fragments of genes required for sulfur oxidation, $\operatorname{sox} B$ encoding sulfate thioesterase/sulfate thiohydrolase and $a p r A$ encoding adenosine- $5^{\prime}$-phosphosulfate reductase, were also amplified by PCR and then sequenced directly. The fragments of the soxB and aprA genes were amplified with the primer pairs soxB432F/soxB1446B (Meyer et al., 2007) and Apr-1-FW/Apr-5-RV (Meyer \& Kuever, 2007), respectively. In the phylogenetic analyses of the functional genes, nucleotide sequences were translated to amino acid sequences. The deduced sequences were aligned with related sequences from the database. Based on the resulting alignment, genetic distances were calculated using the Poisson correction model.

Although strain sk $43 \mathrm{H}^{\mathrm{T}}$ was enriched and isolated by using thiosulfate as sole electron donor, growth on this energy source was rather slow. Hydrogen was tested as an alternative growth substrate, which enhanced lithotrophic growth of the isolate. After that, the isolate was cultured with hydrogen and its properties were determined.

Cells of the isolate were Gram-negative, curved rods (1.0$3.5 \times 0.3-0.5 \mu \mathrm{m})$. Spore formation was not observed. The isolate was catalase-negative and oxidase-positive. Growth was inhibited by kanamycin and ampicillin. The genomic DNA G + C content of the isolate was $67 \mathrm{~mol} \%$.

The isolate could grow anaerobically and heterotrophically in medium containing nitrate on the following substrates $(\mathrm{mM})$ : pyruvate (5), lactate (5), acetate (5), propionate (2.5), succinate (2.5), fumarate (2.5), malate (2.5), benzoate (2.5), butyrate (2.5) and isobutyrate (2.5). All these substrates also supported aerobic growth of the strain. The following substrates $(\mathrm{mM})$ could not support aerobic or anaerobic growth of the novel strain: methanol (5), ethanol (2.5), formate (5), citrate (5), lactose (2.5), glucose (2.5), xylose (2.5) and phenol (2). Under denitrifying conditions, the isolate could grow chemolithotrophically on $\mathrm{H}_{2}\left(\mathrm{H}_{2} / \mathrm{N}_{2} / \mathrm{CO}_{2} ; 50: 40: 10, \mathrm{v} / \mathrm{v} / \mathrm{v} ; 200 \mathrm{kPa}\right.$ total pressure), thiosulfate $(20 \mathrm{mM})$ and $S^{0}\left(0.5 \mathrm{~g} \mathrm{l}^{-1}\right)$. The end product of sulfur oxidation was sulfate. Growth on other inorganic compounds, including sulfide $(2 \mathrm{mM})$, sulfite $(5 \mathrm{mM})$ and $\mathrm{FeSO}_{4}(20 \mathrm{mM})$, was tested but these substrates did not support growth of strain sk $43 \mathrm{H}^{\mathrm{T}}$. Autotrophic growth under aerobic conditions was tested with bicarbonate-buffered medium that contained no nitrate with various concentrations $(20,10$ and $2 \%)$ of $\mathrm{O}_{2}$ in the headspace. In all cases, growth on hydrogen or thiosulfate was not observed.

By using bicarbonate-buffered medium, utilization of electron acceptors was tested using $16 \mathrm{mM}$ acetate as electron donor. The strain could utilize oxygen, at all concentrations, and nitrate $(20 \mathrm{mM})$ as electron acceptors. During growth on nitrate, gas production was observed and nitrite did not accumulate. The following electron acceptors $(\mathrm{mM})$ could not support (or only poorly support) growth of the strain: nitrite (5), sulfite (5), sulfate (10), crystalline iron(III) oxide (10), iron(III) nitrilotriacetic acid (10).

Strain sk $43 \mathrm{H}^{\mathrm{T}}$ was able to grow between 8 and $32{ }^{\circ} \mathrm{C}$, with optimum growth at $25{ }^{\circ} \mathrm{C}$. The $\mathrm{pH}$ range for growth was 


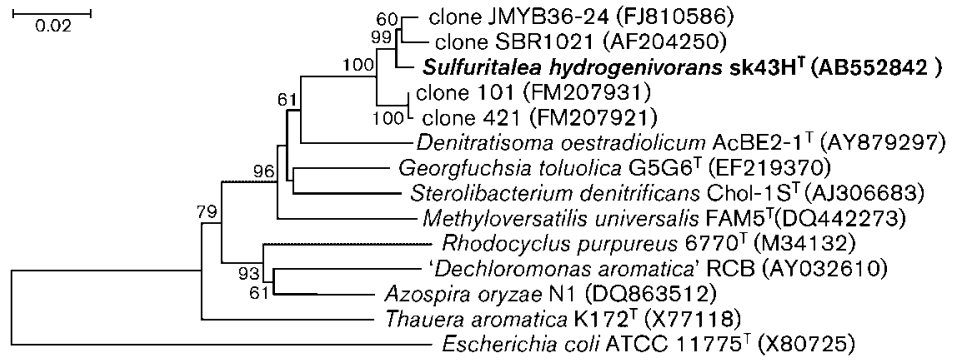

Fig. 1. Phylogenetic position of strain sk43H within the family Rhodocyclaceae based on 16S rRNA gene sequence analysis. The tree was constructed using the minimum-evolution method based on 1405 nucleotide sites. An identical tree was obtained with the neighbourjoining method. Escherichia coli ATCC $11775^{\top}$ (Gammmaproteobacteria) is included as outgroup. Bootstrap values $>50 \%$ (based on 1000 resamplings) are given at nodes. Bar, 0.02 substitutions per nucleotide position.
6.4-7.6, with optimum growth at $\mathrm{pH}$ 6.7-6.9. Optimum growth of the isolate was observed in media containing 0 $50 \mathrm{mM} \mathrm{NaCl}$; only very faint growth was observed in medium containing $240 \mathrm{mM} \mathrm{NaCl}$.

$16 \mathrm{~S}$ rRNA gene sequence analysis revealed that strain sk $43 \mathrm{H}^{\mathrm{T}}$ belonged to the family Rhodocyclaceae of the class Betaproteobacteria (Fig. 1) and did not belong to any known lineage of sulfur-oxidizing bacteria. The closest relative of the isolate was Georgfuchsia toluolica G5G6 ${ }^{\mathrm{T}}$ (94.7\% sequence similarity), a strict anaerobe that degrades aromatic compounds by reducing $\mathrm{Fe}(\mathrm{III})$, $\mathrm{Mn}(\mathrm{IV})$ or nitrate as electron acceptors (Weelink et al., 2009). It has been reported that G. toluolica cannot utilize carboxylic acids or hydrogen as electron donors. Another closely related strain was Denitratisoma oestradiolicum AcBE2- $1^{\mathrm{T}}$ (94.3\% sequence similarity), a denitrifying bacterium capable of degrading $17 \beta$-oestradiol (Fahrbach et al., 2006). It has been shown that D. oestradiolicum cannot grow on benzoate or thiosulfate, both of which support growth of strain sk $43 \mathrm{H}^{\mathrm{T}}$ as sole electron donors. Isolates closely related to strain sk $43 \mathrm{H}^{\mathrm{T}}$ have been identified from nitrifying-denitrifying activated sludge (Juretschko et al., 2002), coal tar waste-contaminated groundwater (Yagi et al., 2010) and enrichment cultures degrading $p$-xylene (Rotaru et al., 2010) (Fig. 1). Following these results, three primer pairs were tested to detect genes involved in degradation of monoaromatic hydrocarbons. The primer pairs used were bssA_f/bssA_r to detect the bssA gene (Botton et al., 2007), BamA-SP9/BamA-ASP1 to detect the bamA gene (Kuntze et al., 2008) and bzAQ4R/ bzAQ4R to detect the bcrA gene (Song \& Ward, 2005). With these primer pairs, however, no PCR product was obtained from the genomic DNA of strain sk $43 \mathrm{H}^{\mathrm{T}}$ (Thauera aromatica $\mathrm{K} 172^{\mathrm{T}}$ was used as a positive control and fragments of the expected sizes were obtained in all cases).

The novelty of strain $\mathrm{sk} 43 \mathrm{H}^{\mathrm{T}}$ was also apparent in the phylogenetic analyses of genes involved in sulfur oxidation, $s o x B$ and aprA (Fig. 2, Fig. 3). As a trial to identify pathways for inorganic carbon fixation, PCR amplifications with primer pairs for the detection of genes involved in the Calvin-Benson-Bassham cycle were also tested. The primer pair cbbLG1F/cbbLG1R (Selesi et al., 2005) and two other primer pairs (Elsaied \& Naganuma, 2001) were used to detect genes $c b b L$ and $c b b M$, encoding forms I and II of ribulose-1,5-bisphosphate carboxylase/oxygenase. None of these primer pairs yielded fragments of the expected size from the genomic DNA of strain sk $43 \mathrm{H}^{\mathrm{T}}$ (Sulfuricella denitrificans $\mathrm{skB} 26^{\mathrm{T}}$ was used as a positive control).

The fatty acid profile of strain sk $43 \mathrm{H}^{\mathrm{T}}$, grown on acetate under aerobic conditions, was characterized by high concentrations of $\mathrm{C}_{16: 0}(33.7 \%)$ and summed feature 3 $\left(\mathrm{C}_{16: 1} \omega 7 c\right.$ and/or iso- $\left.\mathrm{C}_{15: 0} 2-\mathrm{OH} ; 61.2 \%\right)$. Other fatty acids detected were $\mathrm{C}_{14: 0}, \mathrm{C}_{18: 1} \omega 7 c, \mathrm{C}_{16: 1} \omega 7 c$ alcohol, $\mathrm{C}_{16: 0} \mathrm{~N}$ alcohol and $\mathrm{C}_{16: 1} \omega 5 c$ (Supplementary Table S1, available in IJSEM Online). The two major components, $\mathrm{C}_{16: 0}$ and summed feature 3 , were also reported to be major fatty acids of closely related strain D. oestradiolicum

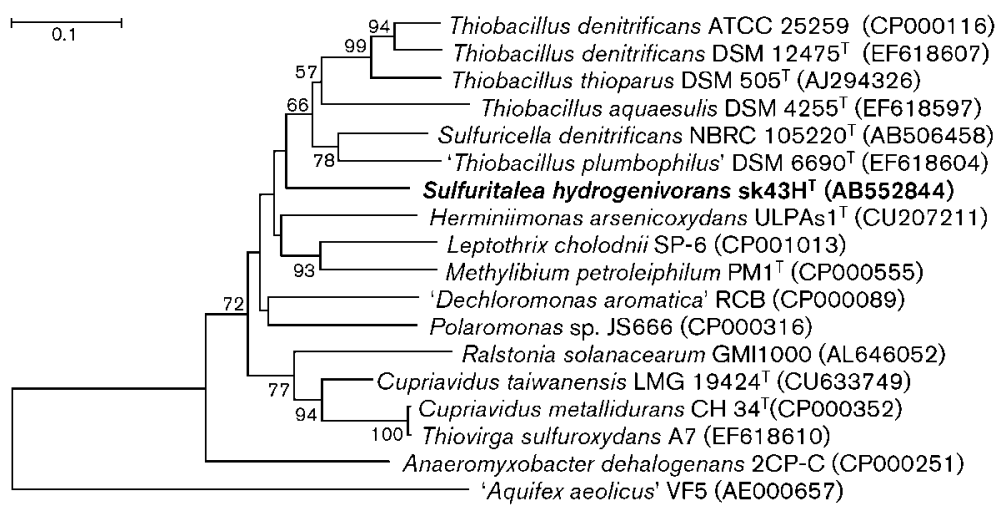

Fig. 2. Phylogenetic position of strain $s k 43 H^{\top}$ based on soxB gene analysis. The minimum evolution tree was constructed from amino acid sequences deduced from sox $B$ gene sequences (235 aa positions were used). 'Aquifex aeolicus' VF5 was used as an outgroup. Bootstrap values $>50 \%$ (based on 1000 resamplings) are given at nodes. Bar, 0.1 substitutions per amino acid position. 


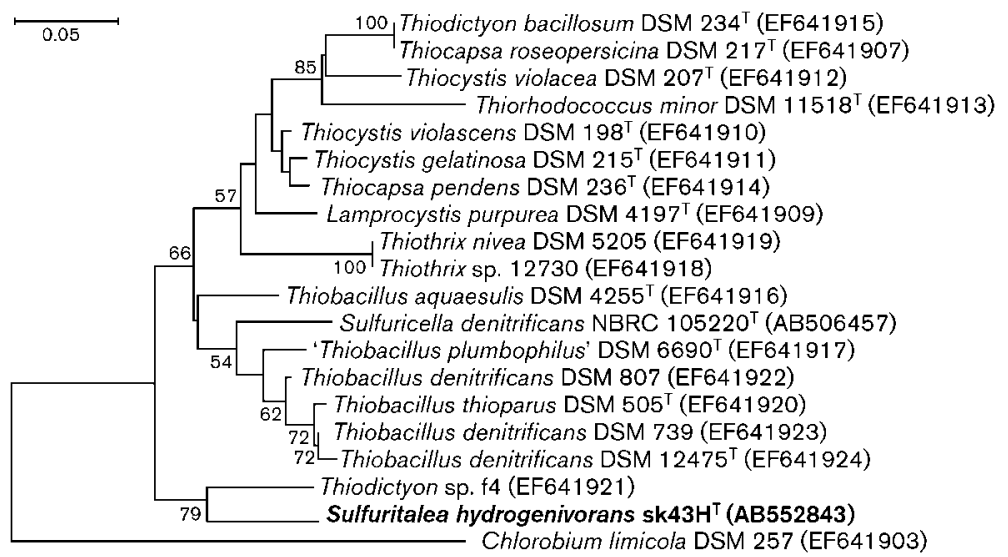

Fig. 3. Phylogenetic position of strain $\mathrm{sk} 43 \mathrm{H}^{\top}$ based on aprA gene analysis. The minimum evolution tree was constructed from amino acid sequences deduced from aprA gene sequences (119 aa positions were used). Chlorobium limicola DSM 257 is included as outgroup. Bootstrap values $>50 \%$ (based on 1000 resamplings) are given at nodes. Bar, 0.05 substitutions per amino acid position.

AcBE2-1 ${ }^{\mathrm{T}}$ grown on acetate under denitrifying conditions. On the other hand, the fatty acid $\mathrm{C}_{18: 1} \omega 7 c$, the third most abundant fatty acid in $D$. oestradiolicum AcBE2 $-1^{\mathrm{T}}$ $(11.8 \%)$, was present in strain sk $43 \mathrm{H}^{\mathrm{T}}$ only as a minor component $(1.2 \%)$. Differences in these two strains were also apparent in the levels of other minor fatty acids (Supplementary Table S1).

Strain sk $43 \mathrm{H}^{\mathrm{T}}$ showed high levels of sequence divergence from related genera. In addition, its physiological characteristics, including chemolithotrophy, differentiated it from related taxa (Table 1). On the basis of these phylogenetic and phenotypic properties, strain sk $43 \mathrm{H}^{\mathrm{T}}$ represents a novel species of a new genus, for which the

Table 1. Differential physiological properties of strain sk43H $\mathrm{H}^{\top}$ and closely related strains

Strains: 1, sk43H ${ }^{\mathrm{T}} ; 2$, Georgfuchsia toluolica $\mathrm{G}^{\mathrm{G}} 6^{\mathrm{T}}$; 3 , Denitratisoma oestradiolicum AcBE2-1 ${ }^{\mathrm{T}} ; 4$, Sterolibacterium denitrificans Chol-1S $\mathrm{S}^{\mathrm{T}}$. +, Growth; -, no growth; ND, not determined. Data were compiled from Weelink et al. (2009), Fahrbach et al. (2006) and Tarlera \& Denner (2003). Nitrate was used as an electron acceptor by all strains studied.

\begin{tabular}{|lcccc|}
\hline Property & $\mathbf{1}$ & $\mathbf{2}$ & $\mathbf{3}$ & $\mathbf{4}$ \\
\hline Electron donors & & & & \\
$\quad$ Acetate & + & - & + & + \\
Lactate & + & - & + & - \\
Succinate & + & - & + & - \\
Fumarate & + & - & + & - \\
Pyruvate & + & - & + & - \\
Isobutyrate & + & - & + & - \\
Benzoate & + & - & - & - \\
Phenol & - & + & - & - \\
Hydrogen & + & - & ND & ND \\
Thiosulfate & + & ND & - & ND \\
Electron acceptors & & & & \\
Oxygen & + & - & + & + \\
Iron(III) & - & + & ND & - \\
\hline
\end{tabular}

name Sulfuritalea hydrogenivorans gen. nov., sp. nov. is proposed.

\section{Description of Sulfuritalea gen. nov.}

Sulfuritalea (Sul.fu.ri.ta'le.a. L. neut. n. sulfur sulfur; L. fem. n. talea a rod; N.L. fem. n. Sulfuritalea sulfuroxidizing rod).

Grows chemolithoautotrophically under anoxic conditions by the oxidation of reduced sulfur compounds and hydrogen. Heterotrophic growth occurs on organic acids. The major fatty acids are $\mathrm{C}_{16: 0}$ and summed feature 3 $\left(\mathrm{C}_{16: 1} \omega 7 c\right.$ and/or iso- $\mathrm{C}_{15: 0}$ 2-OH $)$. Phylogenetically affiliated with the class Betaproteobacteria based on $16 \mathrm{~S}$ rRNA gene sequence analysis. The type species is Sulfuritalea hydrogenivorans.

\section{Description of Sulfuritalea hydrogenivorans sp. nov.}

Sulfuritalea hydrogenivorans (hy.dro.ge.ni.vo'rans. N.L. n. hydrogenum hydrogen; L. part. adj. vorans consuming; N.L. part. hydrogenivorans hydrogen-consuming).

Cells are Gram-reaction-negative, curved rods, 1.0$3.5 \times 0.3-0.5$. Facultatively anaerobic and can reduce nitrate to nitrogen. Autotrophic growth occurs with oxidation of thiosulfate, elemental sulfur and hydrogen. Catalase-negative and oxidase-positive. Heterotrophic growth occurs on acetate, benzoate, butyrate, fumarate, isobutyrate, lactate, malate, propionate, pyruvate and succinate. Grows at $8-32{ }^{\circ} \mathrm{C}$ and $\mathrm{pH}$ 6.4-7.6, with optimum growth at $25{ }^{\circ} \mathrm{C}$ and $\mathrm{pH}$ 6.7-6.9.

The type strain, sk $43 \mathrm{H}^{\mathrm{T}} \quad\left(=\mathrm{DSM} \quad 22779^{\mathrm{T}}=\mathrm{NBRC}\right.$ $105852^{\mathrm{T}}$ ), was isolated from water of a stratified freshwater lake. The DNA G+C content is $67 \mathrm{~mol} \%$.

\section{Acknowledgements}

We thank T. Iwata for donating the sample of lake water and F. Nemoto for assistance in analysis of functional genes. 


\section{References}

Botton, S., van Harmelen, M., Braster, M., Parsons, J. R. \& Röling, W. F. M. (2007). Dominance of Geobacteraceae in BTX-degrading enrichments from an iron-reducing aquifer. FEMS Microbiol Ecol 62, 118-130.

Elsaied, H. \& Naganuma, T. (2001). Phylogenetic diversity of ribulose-1,5-bisphosphate carboxylase/oxygenase large-subunit genes from deep-sea microorganisms. Appl Environ Microbiol 67, 17511765.

Fahrbach, M., Kuever, J., Meinke, R., Kämpfer, P. \& Hollender, J. (2006). Denitratisoma oestradiolicum gen. nov., sp. nov., a $17 \beta$ oestradiol-degrading, denitrifying betaproteobacterium. Int J Syst Evol Microbiol 56, 1547-1552.

Gonzalez, J. M. \& Saiz-Jimenez, C. (2002). A fluorimetric method for the estimation of $\mathrm{G}+\mathrm{C}$ mol\% content in microorganisms by thermal denaturation temperature. Environ Microbiol 4, 770-773.

Juretschko, S., Loy, A., Lehner, A. \& Wagner, M. (2002). The microbial community composition of a nitrifying-denitrifying activated sludge from an industrial sewage treatment plant analyzed by the full-cycle rRNA approach. Syst Appl Microbiol 25, 84-99.

Kojima, H. \& Fukui, M. (2010). Sulfuricella denitrificans gen. nov., sp. nov., a sulfur-oxidizing autotroph isolated from a freshwater lake. Int J Syst Evol Microbiol 60, 2862-2866.

Kojima, H., Iwata, T. \& Fukui, M. (2009). DNA-based analysis of planktonic methanotrophs in a stratified lake. Freshw Biol 54, 1501-1509.

Kumar, S., Tamura, K. \& Nei, M. (2004). MEGA3: integrated software for molecular evolutionary genetics analysis and sequence alignment. Brief Bioinform 5, 150-163.

Kuntze, K., Shinoda, Y., Moutakki, H., Mclnerney, M. J., Vogt, C. Richnow, H. H. \& Boll, M. (2008). 6-Oxocyclohex-1-ene-1-carbonylcoenzyme A hydrolases from obligately anaerobic bacteria: characterization and identification of its gene as a functional marker for aromatic compounds degrading anaerobes. Environ Microbiol 10, 1547-1556.

Lane, D. J. (1991). 16S/23S rRNA sequencing. In Nucleic Acid Techniques in Bacterial Systematics, pp. 115-175. Edited by E. Stackebrandt \& M. Goodfellow. Chichester: Wiley.

Meyer, B. \& Kuever, J. (2007). Molecular analysis of the diversity of sulfate-reducing and sulfur-oxidizing prokaryotes in the environment, using aprA as functional marker gene. Appl Environ Microbiol 73, 76647679.

Meyer, B., Imhoff, J. F. \& Kuever, J. (2007). Molecular analysis of the distribution and phylogeny of the soxB gene among sulfur-oxidizing bacteria - evolution of the Sox sulfur oxidation enzyme system. Environ Microbiol 9, 2957-2977.

Rotaru, A. E., Probian, C., Wilkes, H. \& Harder, J. (2010). Highly enriched Betaproteobacteria growing anaerobically with $p$-xylene and nitrate. FEMS Microbiol Ecol 71, 460-468.

Selesi, D., Schmid, M. \& Hartmann, A. (2005). Diversity of green-like and red-like ribulose-1,5-bisphosphate carboxylase/oxygenase largesubunit genes $(c b b L)$ in differently managed agricultural soils. Appl Environ Microbiol 71, 175-184.

Song, B. \& Ward, B. B. (2005). Genetic diversity of benzoyl coenzyme A reductase genes detected in denitrifying isolates and estuarine sediment communities. Appl Environ Microbiol 71, 2036-2045.

Tarlera, S. \& Denner, E. B. M. (2003). Sterolibacterium denitrificans gen. nov., sp. nov., a novel cholesterol-oxidizing, denitrifying member of the $\beta$-Proteobacteria. Int J Syst Evol Microbiol 53, 1085-1091.

Thompson, J. D., Gibson, T. J., Plewniak, F., Jeanmougin, F. \& Higgins, D. G. (1997). The CLUSTAL_X windows interface: flexible strategies for multiple sequence alignment aided by quality analysis tools. Nucleic Acids Res 25, 4876-4882.

Wang, Q., Garrity, G. M., Tiedje, J. M. \& Cole, J. R. (2007). Naive Bayesian classifier for rapid assignment of rRNA sequences into the new bacterial taxonomy. Appl Environ Microbiol 73, 5261-5267.

Weelink, S. A., van Doesburg, W., Saia, F. T., Rijpstra, W. I., Röling, W. F., Smidt, H. \& Stams, A. J. (2009). A strictly anaerobic betaproteobacterium Georgfuchsia toluolica gen. nov., sp. nov. degrades aromatic compounds with $\mathrm{Fe}(\mathrm{III}), \mathrm{Mn}(\mathrm{IV})$ or nitrate as an electron acceptor. FEMS Microbiol Ecol 70, 575-585.

Widdel, F. \& Bak, F. (1992). Gram-negative mesotrophic sulfatereducing bacteria. In The Prokaryotes, 2nd edn, vol. 4, pp. 3352-3378. Edited by A. Balows, H. G. Trüper, M. Dworkin, W. Harder \& K.-H. Schleifer. New York: Springer-Verlag.

Yagi, J. M., Neuhauser, E. F., Ripp, J. A., Mauro, D. M. \& Madsen, E. L. (2010). Subsurface ecosystem resilience: long-term attenuation of subsurface contaminants supports a dynamic microbial community. ISME J 4, 131-143. 